\title{
Pituitary Hypothyroidism
}

National Cancer Institute

\section{Source}

National Cancer Institute. Pituitary Hypothyroidism. NCI Thesaurus. Code C121743.

Hypothyroidism due to dysfunction of the pituitary gland, which results in inadequate secretion of thyroid-stimulating hormone (thyrotropin). 